\title{
Reinnervation of the rectum with a somatic nerve: a canine study
}

\author{
Ahmed Shafik \\ Professor and Chairman, Department of Surgery and Experimental Research, Faculty of Medicine, Cairo University, \\ Cairo, Egypt
}

\begin{abstract}
The purpose of this communication was to evaluate the possibility of rectal stimulation through nerve autografting. Eleven mongrel dogs were studied. The abdomen was opened under anesthesia. The obturator nerve was cut at its entrance into the obturator foramen and was embedded in a tunnel within the musculature of the rectal wall. Six months later, the abdomen was re-opened and bilateral pelvic ganglionectomy was done to denervate the rectum. As the urinary bladder was also denervated subsequent to the pelvic ganglionectomy, cystostomy was performed. Two bipolar electrodes were applied to the obturator nerve. The effects of electrostimulation were evaluated under basic conditions after urecholine and atropine administration and after xylocaine topical application to the obturator nerve.

After bilateral pelvic neurectomy, the basic rectal pressure dropped $(P<0.05)$ and there was no response to urecholine or to atropine injection. Obturator nerve electrostimulation induced evoked potentials within the nerve as well as rectal pressure rise $(P<0.001)$; the former was abolished with xylocaine topical application to the nerve and the latter with atropine administration. Microscopic examination revealed that the Schwann cells and axons grew in the connective tissue between the rectal muscle bundles.

In conclusion, reinnervation of the denervated rectum using a somatic nerve implant is possible. To our knowledge this study is the first to show 'smooth' muscle excitability by stimulation of a somatic nerve implant.
\end{abstract}

Keywords: rectal inertia; neuropathic rectum; rectal reinnervation; constipation

\section{Introduction}

Defecation is dependent on a reflex arc situated at the level of S2, S3 and S4 and is mediated via the pelvic nerve. ${ }^{1}$ Spinal cord lesions destroy this reflex with resulting evacuation disorders. Various methods with varying results have been used to restore the rectal detrusor function in these cases including the application of an artificial pacemaker ${ }^{2,3}$ ventral sacral root stimulation ${ }^{4}$ enemas, and laxatives.

Investigators have shown that the axons of myelinated nerves of the somatic efferent grow down the sheaths originally containing axons of the autonomic nervous system and vice versa. ${ }^{5,6}$ The result of stimulation of the regenerated nerve depends not on the type of fibers in the donor nerve but on the target organ. ${ }^{5,6}$ Anastomosis between the obturator and pelvic nerves in dogs resulted in bladder contraction upon obturator nerve stimulation proximal to the anastomosis. ${ }^{7} 8 \mathrm{Kummel}^{8}$ performed the same experiments in rats with crossed anastomoses between the hypogastric and pelvic nerves and the obturator and pelvic nerves. Obturator nerve stimula-

Correspondence: Ahmed Shafik, 2 Talaat Harb Street, Cairo, Egypt tion produced a small intravesical pressure rise whereas no response occurred upon stimulation of the regenerated hypogastric nerve.

The effect of implanting somatic motor nerves directly into the muscular coat of various canine viscera was studied by Ottavian. ${ }^{9}$ He noted that there was cystometric evidence of increased vesical tone after regeneration of the implanted nerve. Rao et al studied the results of somatic motor nerves implantation into the detrusor of the denervated urinary bladder. ${ }^{10}$ Neuroma was detected at the site of implantation with axons spreading a short distance into the adjacent bladder wall. There was no intravesical pressure rise on stimulation of the implanted nerve.

The purpose of this communication was to evaluate the possibility of rectal stimulation through nerve autografting aiming at applying this technique for the neuropathic rectum of patients with spinal cord injuries.

\section{Materials and methods}

Eleven mongrel dogs with a mean weight of $17.6 \pm 2.8 \mathrm{SD} \mathrm{kg}$ (range 14-21) were studied. Seven were male and four female. All animals were treated 
according to the guide for the care and use of laboratory animals. ${ }^{11}$

Before producing rectal denervation the rectal pressure was measured by means of a $6 \mathrm{~F}$ tube with a side port which was perfused with $37^{\circ} \mathrm{C}$ saline at a rate of $1.6 \mathrm{ml} / \mathrm{min}$ and connected to a pressure gauge transducer (Statham, 230 B, Oxnard, California). The response of the rectal pressure to an intravenous injection of $1 \mathrm{mg}$ of bethanechol chloride (urecholine) and $5 \mathrm{mg}$ of atropine, respectively, was recorded.

\section{Methods}

Pre-operatively the dogs were fasting for $12 \mathrm{~h}$. The bowels were evacuated by a saline enema. Surgery was done under aseptic conditions and antibiotic coverage (3rd generation cephalosporin).

The animals were premedicated with diazepam in a dose of $0.4 \mathrm{mg} / \mathrm{kg}$ body weight (bw), administered intramuscularly. They were anesthetized with intravenous pentobarbital in a dose of $30 \mathrm{mg} / \mathrm{kg}$ bw with a bolus injection of $20-25 \mathrm{mg} / \mathrm{h}$ to maintain adequate anesthesia with spontaneous respiration. Intravenous infusion of normal saline was given in a dose of $2 \mathrm{ml} /$ $\mathrm{kg} \mathrm{bw} / \mathrm{h}$.

With the animal lying supine, the abdomen of the dog was opened through a midline incision. The obturator nerve was exposed in the side wall of the pelvis. The nerve after emerging from the caudomedial portion of the iliopsoas muscle, crosses the common iliac vein and enters the pelvis. It runs across the laterally lying shaft of the ilium to enter the obturator foramen. The nerve was exposed and divided at its entrance into the obturator foramen.

The rectum was identified and a longitudinal $2-$ $3 \mathrm{~cm}$ myotomy incision was performed on the ipsilateral side of the transected obturator nerve (Figure 1). The myotomy comprised division of the rectal muscle coat down to, but not including, the mucosa. The free end of the mobilized nerve (1.5$2 \mathrm{~cm}$ ) was embedded in the myotomy incison. The nerve was fixed by two stitches of $8 / 0$ nylon to the wall of the rectal tunnel at the site of entry. The stitches were passed between the perineurium and the rectal muscle coat using a magnifying loupe. The walls of the rectal tunnel were then sutured over the embedded nerve (Figure 1).

Six months later, the abdomen was re-opened and the right and left pelvic ganglia were excised (bilateral pelvic ganglionectomy). The obturator nerve was exposed as it came out of the iliopsoas muscle and two bipolar electrodes were applied to it. As pelvic ganglionectomy paralyses not only the rectum but also the urinary bladder, cystostomy for urine drainage was done at the same sitting.

Two weeks were allowed post-operatively for the wounds to heal. The urecholine test was repeated to confirm rectal denervation. The implanted obturator nerve was electrically stimulated and the rectal pressure was recorded. Stimulation pulses were

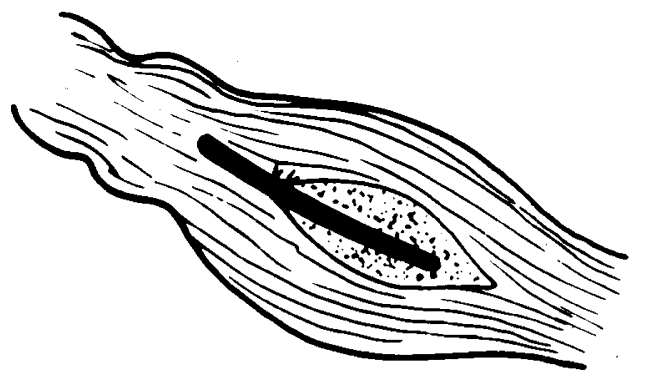

b

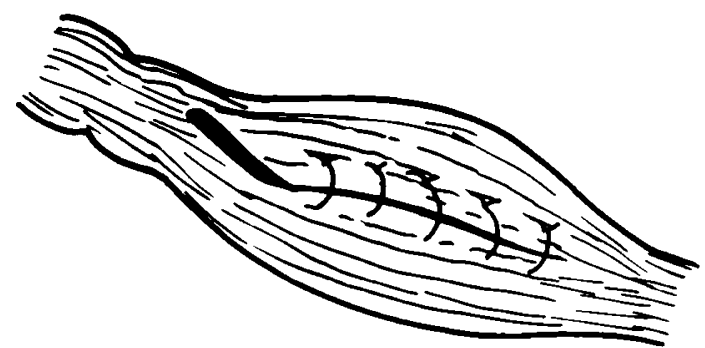

Figure 1 Steps of obturator nerve implantation into the rectal muscle coat (a) The divided obturator nerve is put into the myotomy incision and stitched to the muscle coat (b) The myotomy incision is closed over the implanted nerve

delivered by a signal generator (Hewlett-Packard 8012B, Hewlett-Packard, Palo Alto, California, USA). The effects of electrostimulation were evaluated under basic conditions and after intravenous administration of urecholine and atropine.

To test whether rectal response to obturator nerve stimulation was a result of specific obturator nerve stimulation or non-specific spread of the current, $1 \mathrm{ml}$ of 2\% xylocaine (Astra, Sodertalje, Stockholm, Sweden) was applied to the obturator nerve after pelvic ganglionectomy in the second laparotomy. The obturator nerve was stimulated as aforementioned and the rectal pressure was determined before and after xylocaine application.

At the end of the experiment, a histological study of the rectal and nerve implant tissues was performed. Biopsies were taken from the rectum at the junction of the obturator nerve termination with rectal musculature. Serial sections were done and stained with hematoxylin and eosin and Verhoeff-van Gieson stain. The results were analyzed statistically using the Student's $t$ test. Significance was ascribed to $P<0.05$. Values were given as mean \pm standard deviation (SD).

\section{Results}

Two dogs did not survive the 6 month study period. One dog died 2 months and the other 110 days after the first operation. Post-mortem examination showed excessive intestinal adhesions in the two dogs. The remaining nine dogs survived until the end of the study and all were evaluated. 
Before the first operation, the mean resting rectal pressure was $7.2 \pm 1.4 \mathrm{~cm} \mathrm{H}_{2} \mathrm{O}$ (range 4-9). It rose after injection of $1 \mathrm{mg}$ urecholine to a mean of $36.4 \pm 10.2 \mathrm{~cm} \mathrm{H}_{2} \mathrm{O}$ (range 28-46; $P<0.01$ ) and dropped after $5 \mathrm{mg}$ atropine injection to $3.3 \pm 0.8 \mathrm{~cm}$ $\mathrm{H}_{2} \mathrm{O}$ (range $2-5 ; P<0.05$ ).

At the second operation, the nerve graft was found lying in the tunnel formed by the rectal muscle coat. After pelvic ganglionectomy, the resting rectal pressure dropped to a mean of $4.6 \pm 0.9 \mathrm{~cm} \mathrm{H}_{2} \mathrm{O}$ (range $3-6 ; \quad P<0.05$ ) and no significant rectal pressure response occurred to either $1 \mathrm{mg}$ urecholine or $5 \mathrm{mg}$ atropine intravenous injection $(P>0.05)$. Electric stimulation of the obturator nerve $(0.15$ to $0.5 \mathrm{~V}, 2$ pulses $/ \mathrm{s}$ and $0.1 \mathrm{msec}$ duration) induced evoked potentials within the nerve and a mean rectal pressure rise of $28.5 \pm 7.4 \mathrm{~cm} \mathrm{H}_{2} \mathrm{O}$; (range 24-39; $P<0.001$; Figure 2). Intravenous administration of $5 \mathrm{mg}$ atropine abolished the rectal pressure response to obturator nerve stimulation (Figure 3), whereas $1 \mathrm{mg}$ urecholine injection had no effect on the response. Xylocaine topical application to the obturator nerve abolished both the evoked potentials within the nerve and the rectal pressure rise upon obturator nerve stimulation.
The aforementioned results were reproducible when the test was repeated in the same animal with no significant difference $(P>0.05)$.

Microscopic examination revealed that the Schwann cells and axons grew in the connective tissue between the rectal muscle bundles (Figure 4). There was no neuroma formation. Synaptic connections could not be demonstrated between the implanted nerve fibres and the muscle bundles.

\section{Discussion}

Pelvic ganglionectomy resulted in rectal paralysis as shown by drop of the rectal pressure as well as abolition of the response to urecholine and atropine intravenous administration. Cystostomy was performed for the expected vesical paralysis. Pelvic ganglionectomy was not done during the first operation as evacuation troubles and vesical infection might have occurred during the 6 months period of awaiting rectal innervation to occur from the implanted obturator nerve. Performing it at 6 months after nerve implantation, the above complications could be avoided and at the same time, the result of nerve autografting assessed.

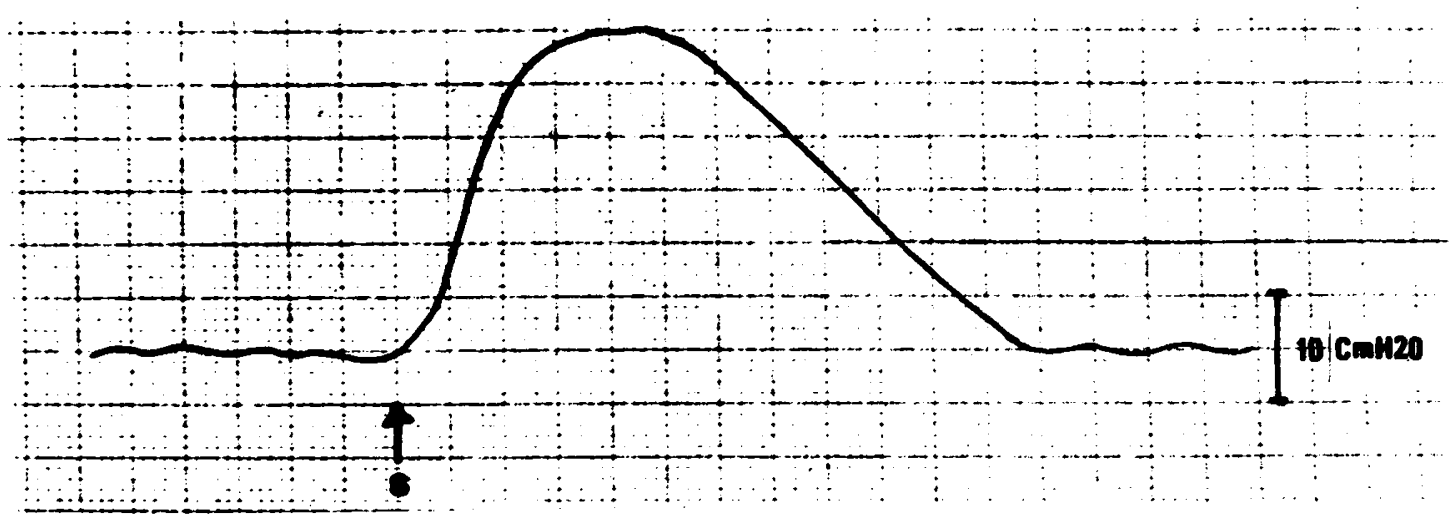

Figure 2 Response of the neuropathic rectum to obturator nerve stimulation. $\mathrm{S}=$ stimulus

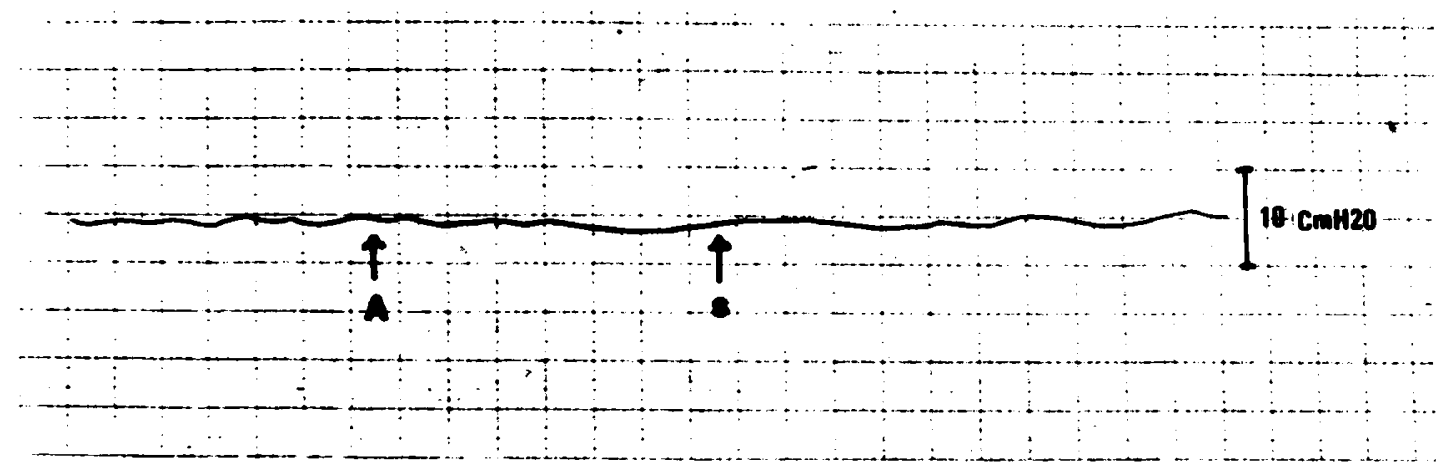

Figure 3 Response of rectum to obturator nerve stimulation after atropine administration. $\mathrm{A}=$ atropine, $\mathrm{S}=$ stimulus 
a

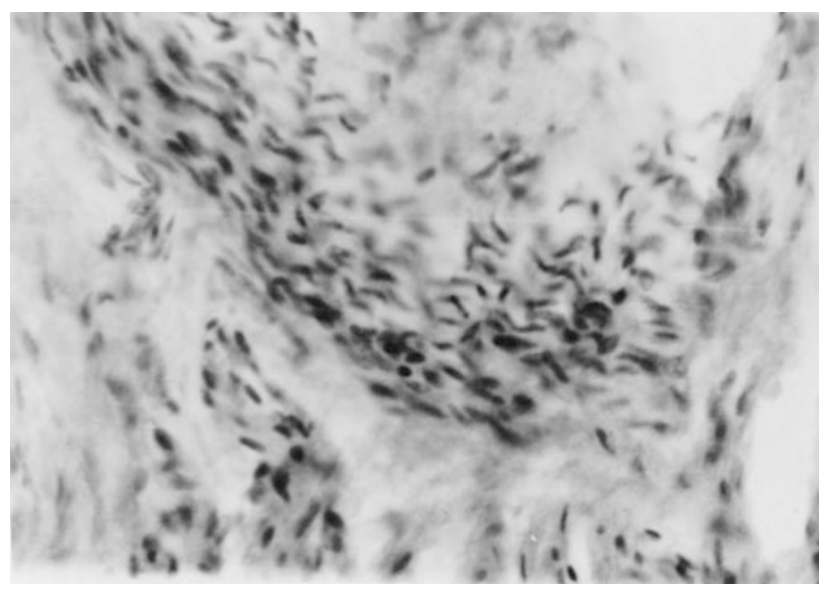

b

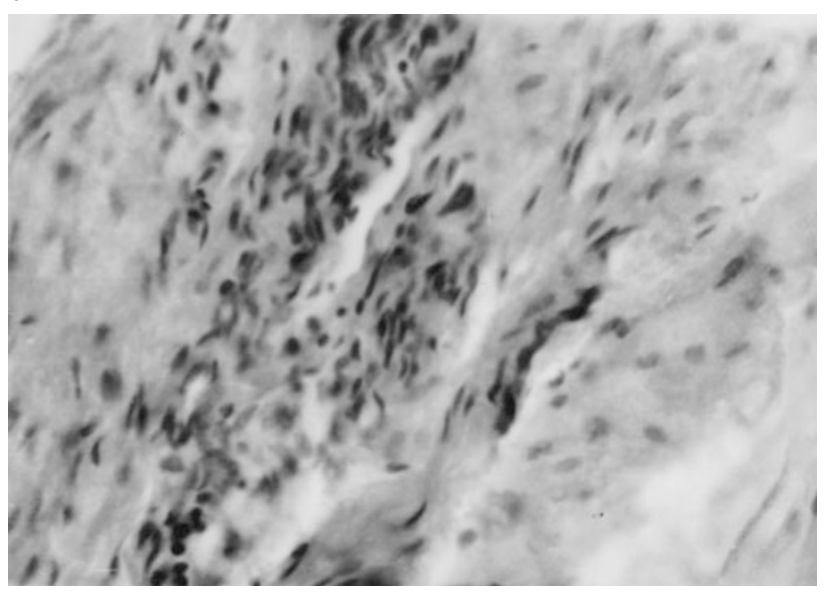

C

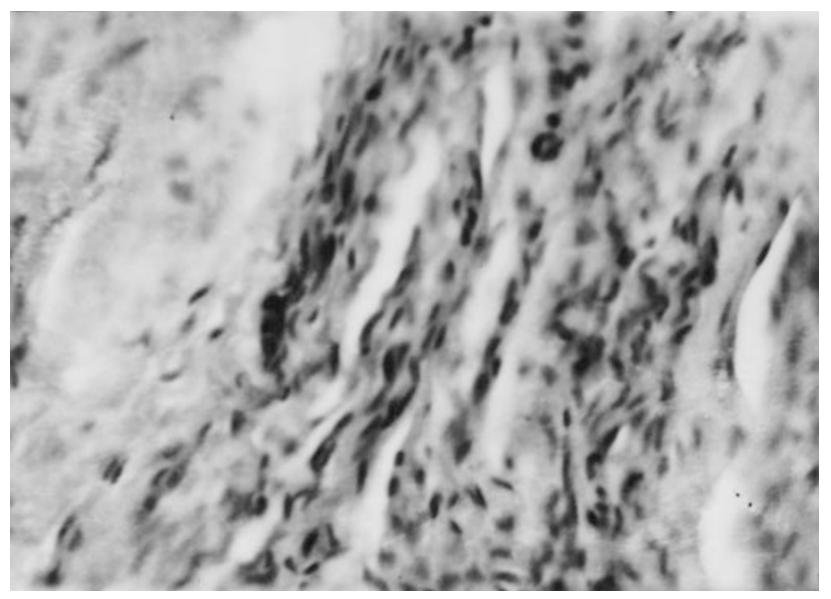

Figure 4 Photomicrograph of 3 specimens (a, b and c) showing the obturator nerve fibers growing in the connective tissue between the rectal muscle bundles (hematoxylin and $\operatorname{eosin} \times 400$ )
The current study demonstrated that 6 months after obturator nerve implantation into the rectal wall, the rectal pressure increased upon electric stimulation of the nerve. This would indicate that rectal contraction and reinnervation had occurred. It may be assumed that rectal contraction upon stimulation of the implanted obturator nerve resulted from nonspecific spread of the current and was not a result of specific obturator nerve stimulation. However, such a proposition may be negated by the fact that xylocaine topical application of the obturator nerve abolished both the evoked potentials within the nerve and the rectal pressure rise upon obturator nerve stimulation.

The obturator nerve vitality was evidenced by the presence of the evoked potentials. Microscopically, the nerve fibres grew between the muscle bundles with no neuroma formation. As atropine, an acetylcholine antagonist, abolished the rectal pressure response to obturator nerve stimulation, it is suggested that acetylcholine is liberated from the obturator nerve endings and might act directly on the rectal muscle bundles. Alternatively, acetylcholine might function through synaptic connections between the nerve implant and the 'smooth' muscle bundles. In the current study, we could not demonstrate such synapses. However, synaptic formation has been shown to occur between 'striated' muscles and transposed unrelated nerves. ${ }^{12}$ It may be argued that possibly the impulses in the transplanted obturator nerve act through the scattered ganglion cells in the rectal wall. However, the bilateral pelvic ganglionectomy which had been performed seems to negate such a possibility.

In conclusion, reinnervation of the denervated rectum using the somatic nerve implant is possible. These are preliminary results and further studies are needed before embarking on clinical application. To our knowledge, this study is the first to show 'smooth' muscle excitability by the stimulation of a somatic nerve implant.

\section{Acknowledgements}

Abdalla Khalil MD, PhD, Professor of Histopathology, interpreted the rectal biopsies histologically. Waltraut Reichelt and Margot Yehia assisted in preparing the manuscript.

\section{References}

1 Henry MM, Swash M. Fecal continence, defecation and colorectal motility. In: Henry MM, Swash M (eds). Coloproctology and the Pelvic Floor: Pathophysiology and Management. Butterworths: London, UK, 1985; pp. 42-52.

2 Shafik A. Rectosigmoid pacemaker: Role in the mechanism of defecation. Dig Surg 1993; 10: $95-100$.

3 Shafik A. Artificial pacemaker for rectal evacuation. Coloproctology 1992; 14: $96-98$.

4 Shafik A. Sacral root stimulation for controlled defecation. Eur Surg Res 1995; 27: $63-68$. 
5 Langley JN. Note on regeneration of preganglionic fibers of the sympathetic. J Physiol (London) 1985; 18: 280-298.

6 Beattie J, Duel AB, Ballance C. The effects of stimulation of the hypothalamic pupil dilator center after successful anastomoses between the cervical sympathetic and certain motor nerves. $J$ Anat 1931; 66: $283-288$.

7 Trumble HC. Experimental reinnervation of the paralyzed bladder. Med J Aust 1935; 1: $118-122$.

8 Kummel DL. Urinary bladder function in rats following regeneration of direct and crossed nerve anastomosis. Chicago Med Sci Quart 1966; 26: 112 - 126.
9 Ottaviani G. Aspetti istologici della rigenerazione del moncone centrale del nervo otturatore innestato nella parete vesicale. Boll Soc Ital Sper 1939; 14: 623-629.

10 Rao CR, Bruce AW, Lywood DW, Robertson DM. Reinnervation of the neurogenic bladder with somatic motor nerves. Invest Urol 1971; 9: 59-63.

11 The guide for care and use of laboratory animals. US Public Health Services NIH Pub No. 1: 5-23.

12 Sanes JR. Regeneration of synapses. In: Nicholls JC (ed). Repair and regeneration of the nervous system. Life Science Research Report 224: Springer Verlag, New York, 1982; p. 128 